DF:PARTAMENTO DE FISIOLOGIA

Diretor: Prof. Dr. Ozlel Bizutt

\title{
NIVEI: SANGUínEOS DE TRANSAMINASE GLAUTÁMICO PIRITVICA, TRANSAMINASE GLUTÂMICO OXALOACÉTICA, FOSFATASES ÁCIDA E ALCALINA E AMILASE, DURANTE A PRENHEZ E O PÓS-PARTO DA ÉGUA PURO SANGUE INGLÊS
}

(BLOOD SERUM LEVELS OF SGP-T, SGO-T. ALKALINF. AND ACID PHOSPHATASFS AND AMYLASE, DURING PREGNANCY AND POST PARTUM PERIODS OF THE THOROUGHBRED MARES )

\author{
O. BIZI"rTI \\ Prof, Assistente Doutor \\ M. E. M. OI.IIEIRA \\ Prof. Assistento
}

J. F. TABRREILLI NETO Prof. Catedrático

F. GaCE:

Prof. Assistente

\section{INTROIJUÇAO}

Modificaçōes nos niveis normais das enzimas são atualmente de valor, não só para orientação do clinico em uma série de doenças, como também para o reconhecimento de certos desvios metabólicos.

Isto decorre do fato, já descrito, de que as variaçōes nos teores normais das enzimas presentes no sôro podem manifestar-se, quer por desequilibrio bioquímico ao nivel da célula, como sói acontecer, exemplificando, nas alterações da permeabilidade celular.

Tendo em mira as possiveis modificaçōes metabólicas presentes durante a gestação, procurou-se analisar neste trabalho, os niveis séricos das seguintes enzimas: transaminase glutâmico pirúvica (SGP-T), transaminase glutâmico-oxalacética (SGO-T), fosfatase alcalina, fosfatase ácida e amilase, durante a prenhez da égua puro sangue inglês (p.s. i).

\section{LITERATURA}

A literatura existente, não só quanto ao objetivo ora proposto como também no que tange a espécie animal referida, é reduzida, muito embora seja extensa a bibliografia concernente aos teores séricos de determinadas enzimas $\mathrm{em}$ diferentes espécies animais 
quando submetidas a inúmeras $\mathrm{e}$ diferentes condiçōes, quer normais, quer patológicas.

\section{MATFETAI, F, METODOS}

\section{Animais utilizados}

As 12 éguas utilizadas no presente trabalho pertenciam ao mesmo haras, localizado nas proximidades da cirlade de Campinas, Estado de sião Paulo, e eram da raça puro sangue inglês de corrida (p.s. i).

Tinham assistência veterinária peımanente, sendo consideradas clinicamente sadias, dentro das garantias que o exame clínicn oferece.

Recebiam tratamento semelhante quanto ao manéjo, sobretudo no referente à alimentação e ao número de horas de pastejo por dia. Eram mantidas em seus boxes durante a noite e soltas no pasto pela manhã.

\section{Coleta do material e tratamento subseqüente}

Por ocasiāo da coleta do sangue, material que utilizamos no presente trabalho para a realização das diferentes técnicas abaixo descritas, os animais eram trazidos do pasto para os boxes, lugar onde eram sangrados imediatamente.

A coleta realizou-se sempre no periodo da manhā, entre 9:30 e 12:00 horas, por punçāo da veia jugular com agulha 40x20.

As éguas eram sangradas pela primeira vez ao redor do 30 dia da suposta prenhez, sendo as coletas subseqüuentes efetuadas a intervalos de 20 dias, até 10 a 30 dias após o parto.

O sangue armazenado em frascos de boca larga, era imedialamente colocado em geladeira portátil e transportado para o laboratório, sendo o sôro recolhido após coagulação e descolamento do coảgulo.

\section{Dosagem das enzimas}

No mesmo dia da coleta, procedia-se a dosagem das transami. nases e das fosfatases e no dia seguinte, à da amilase. Para as primeiras, empregou-se o método de Reit'Mian e FRANkEL (8); para as duas últimas, a técnica de $\mathrm{KING}$, de acôrdo com os métodos descritos por BACILA e cols. (1).

\section{Análise estatistica}

Foi realizado, para cada grupo de resultados, a análise da variância $c$, tendo-se encontrado valores significantes, aplicou-se o teste de DUNCAN, conforme GoMes (5). 


\section{RFSULTADOS}

Para a interpretação dos resultados, o periodo de gestação foi agrupado em 6 classes dispostas com intervalo de 50 dias, partindo-se do 30" c encerrando-se no 330" dia. Nova classe foi constituida pelas coletas efetuadas entre 10 e 30 dias após o parto.

Foram considerados tão sumente os resultados obtidos com amostras colhidas nos dias de gestação correspondentes, aproximadamente, ao valor médio de cada classe, isto é, com 55, 105, 155, $205,255,305$ e 20 dias, respectivamente.

Os resultados referentes às variaçōes nos teores séricos das enzimas estudadas, durante a prenhez das éguas $\mathrm{cm}$ observação, encontram-se nas tabelas de n:s 1 a 5 . Às tabelas seguem-se as figuras de n's 1 a 5 relativas a cada um dos elementos estudados no presente trabalho.

Para a análise da variância de todos os resultados obtidos, o nivel de rejeição adotado foi sempre de $5 \%$.

Com relaçāo às enzimas, fosfatase ácida, transaminase glutâmico-pirúvica e transaminase glutâmico-oxalacética, a análise revelou, como pode ser observado nas tabelas 4,1 e 2, nāo haver significância nos resultados obtidos, à despeito da queda acentuada na curva da transaminase glutâmico-oxalacética ao redor do 130 " dia da prenhez (figura n" 2). Todavia, houve significância quanto aos dados referentes à amilase (tabela 5 e figura 5) e à fosfatase alcalina (tabela 3 e figura 3 ).

Assim, para os contrastes entre as médias das enzimas referidas, medias estas correspondentes aos diferentes intervalos de tempo após a cobertura e o parto, aplicou-se, como já salientou, o teste de DunCan, o qual demonstrou o seguinte:

a) no referente à fosfatase alcalina, no periodo compreendido entre 30 e 280 dias do inicio da prenhez, não houve diferença significante entre as médias dos niveis obtidos. Na fase da gestação compreendida entre 280 e 330 dias, bem como no periodo de 10 a 30 dias após o parto, as médias dos niveis encontrados nāo diferiram significantemente entre si, mas diferiram significantemente das médias dos intervalos de 30 a 280 dias após a cobertura;

b) no referente à amilase, não houve diferença significativa entre as médias dos niveis encontrados, durante o periodo compreendido entre 80 a 280 dias da prenhez. As médias obtidas, para os niveis relativos aos periodos de 30 a 80 e de 280 a 330 dias após a cobertura, e de 10 a 30 dias após o parto, também não diferiram significantemente entre si. Entretanto, o grupo de médias referentes aos três últimos intervalos citados, diferiu significantemente do grupo de médias concernentes ao periodo que vai de 80 a 280 dias de gestação. 
Tabela 1 - Transaminase glutamica pirúvica (SGP-T): no sōro de eguas p.s. i. (lurante a gestacāo e após parto. Os valores inclicadlos regresentam unidades Rejtman-Frankel por $\mathrm{m} 1$ de sôro.

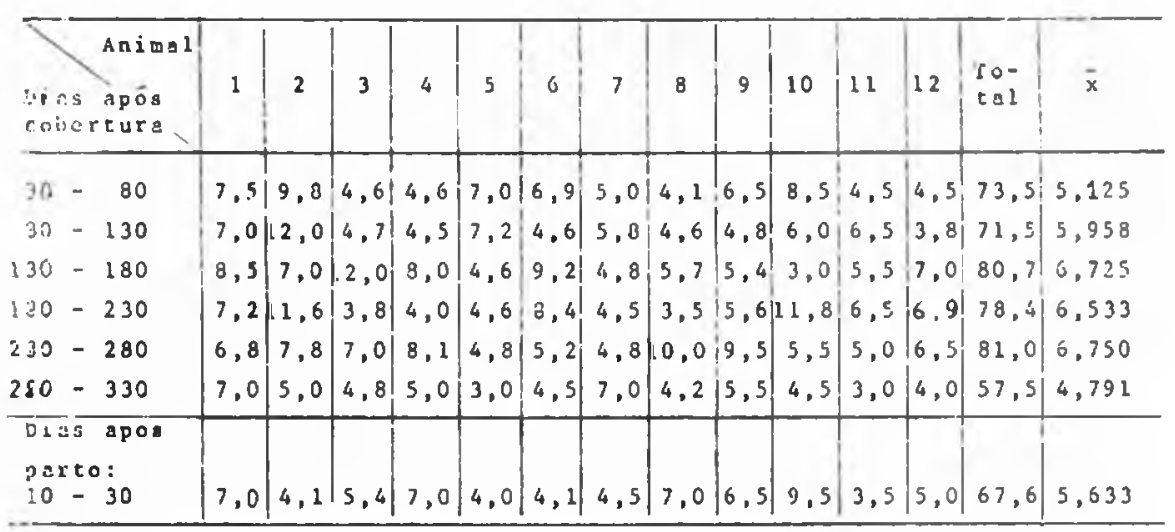

ANÁLISF. DA VARIANCIA

\begin{tabular}{l|r|r|r|c}
\hline $\begin{array}{l}\text { Fonte de } \\
\text { variaçäo }\end{array}$ & g.l. & S.Q. & Q.M. & F \\
\hline $\begin{array}{l}\text { Tratamentos } \\
\text { Residuo }\end{array}$ & 6 & 35,34 & 5,8900 & 1,35 \\
\hline Total & 33 & 333,98 & 4,3375 & \\
\hline
\end{tabular}


rabela II - Transaminase glutamica oxaloancettca (SGO-T): no sōro de eguas p.s. Thes durante a gestacăo e após parto. Os valores indlicados
Reltman-Frankel por ml de sōro.

\begin{tabular}{|c|c|c|c|c|c|c|c|c|c|c|c|c|c|c|}
\hline $\begin{array}{l}\text { Animel } \\
\text { Dias após } \\
\text { coberturs }\end{array}$ & 1 & 2 & 3 & 4 & 5 & 6 & 7 & 6 & 9 & 10 & 11 & 12 & $\begin{array}{l}\text { To- } \\
\text { tal }\end{array}$ & $\bar{x}$ \\
\hline $30-80$ & 190 & 108 & 120 & 130 & 130 & 180 & 120 & 120 & 130 & 130 & 120 & 123 & 1651 & 137,583 \\
\hline $80-130$ & 180 & 92 & 100 & 140 & 110 & 130 & 170 & 130 & 130 & 150 & 110 & 124 & 1574 & 131,166 \\
\hline $130-180$ & 128 & 120 & 126 & 128 & 115 & 110 & 118 & 150 & 125 & 110 & 100 & 108 & 1438 & 119.833 \\
\hline $180-230$ & 146 & 130 & 92 & 130 & 120 & 130 & 100 & 150 & 120 & 130 & 90 & 150 & 1488 & 124,000 \\
\hline $230-280$ & 150 & 110 & 110 & 120 & 125 & 120 & 140 & 108 & 125 & 123 & 130 & 180 & I 541 & 123,416 \\
\hline $280-330$ & 130 & 109 & 135 & 130 & 135 & 130 & 123 & 115 & 150 & 135 & 108 & 120 & 1520 & 126,666 \\
\hline $\begin{array}{l}\text { Lias घpós } \\
\text { parto: } \\
10-30\end{array}$ & 125 & 123 & 96 & 120 & 135 & 109 & 118 & 130 & 150 & 142 & 109 & 142 & 1499 & 124,916 \\
\hline
\end{tabular}

ANALISF DA VARIANCIA

\begin{tabular}{|c|c|c|c|c|}
\hline $\begin{array}{l}\text { Ponte de } \\
\text { variaçao }\end{array}$ & 8.1 & S.Q. & Q.11. & $\mathbf{F}$ \\
\hline Tratamentos & 6 & 2332 & 388,666 & 0,94 \\
\hline Residuo & 77 & 31773 & $412.636 \mathrm{p}$ & \\
\hline Total & 83 & 34105 & & \\
\hline
\end{tabular}


Tahela III - Fosfatase alcalina: no sôro de éguas p.s. i. đurante a gestacāo e àós Tarto. Os ralores indicudos representsm unidacles King Armstrong por $100 \mathrm{~m} 1$ de söro.

\begin{tabular}{|c|c|c|c|c|c|c|c|c|c|c|c|c|c|c|}
\hline $\begin{array}{l}\text { Animal } \\
\text { Dies após } \\
\text { cobertura }\end{array}$ & 1 & 2 & 3 & 4 & 5 & 5 & 7 & 8 & 9 & 10 & 11 & 12 & $\begin{array}{l}\text { To- } \\
\text { tal }\end{array}$ & $\bar{x}$ \\
\hline $30-80$ & 23,0 & 23,4 & 23,0 & 20,4 & 24,2 & 27,0 & 25,0 & 23,9 & 23,1 & 25,5 & 24,8 & 21,0 & 285,2 & 23,766 \\
\hline $80-130$ & 25,3 & 20,7 & 23,0 & 24,0 & 23,4 & 21,6 & 27,3 & 22,8 & 18,1 & 22,5 & 25,0 & 23,0 & 276,7 & 23,058 \\
\hline $130-180$ & 21,9 & 25,4 & 27,0 & 22,3 & 22,3 & 30,8 & 25,2 & 29,5 & 23,2 & 23,3 & 25,0 & 21,1 & 297,0 & 24,750 \\
\hline $180-230$ & 27,0 & 25,2 & 30,6 & 20,0 & 25,0 & 29,0 & 21,0 & 25,0 & 23,0 & 23,3 & 24,0 & 21,0 & $294, ?$ & 24,508 \\
\hline $230-280$ & 22,9 & 23,3 & 26,2 & 21,0 & 16,4 & 27,8 & 20,9 & 27,8 & 22,0 & 28,1 & 20,1 & 24,3 & 280,8 & 23,400 \\
\hline $280-330$ & 18,0 & 19,8 & 23,0 & 22,7 & 22,5 & 23,4 & 19,2 & 22,0 & 23,0 & 22,2 & 17,9 & 18,4 & $25 ?, 1$ & 21,008 \\
\hline $\begin{array}{l}\text { Dias apōs } \\
\text { parto: } \\
10-30\end{array}$ & 27,0 & 15,6 & 22,0 & 24,6 & 20,0 & 21,3 & 24,8 & 27,0 & 18,9 & 24,8 & 20,0 & 18,0 & 264,0 & 22,000 \\
\hline
\end{tabular}

\begin{tabular}{|c|c|c|c|c|}
\hline $\begin{array}{l}\text { Fonte de } \\
\text { variaçäo }\end{array}$ & g. 1 . & $S \cdot Q$. & Q.li. & $\mathbf{F}$ \\
\hline Tracamencos & 6 & 128,85 & 21,475 & $2,52^{*}$ \\
\hline Residuo & 77 & 655,61 & 8,51442 & \\
\hline Total & 83 & 784,46 & & \\
\hline
\end{tabular}


Tabela IV ... Fosfatase ácida: no sono de eguas p.s. i. durante a gestacăo e após

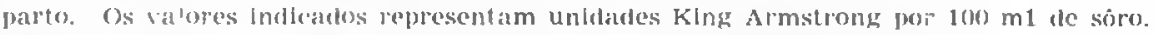

\begin{tabular}{|c|c|c|c|c|c|c|c|c|c|c|c|c|c|c|}
\hline $\begin{array}{l}\text { Animal } \\
\text { Dias apóa } \\
\text { cobertura }\end{array}$ & 1 & 2 & 3 & 4 & 5 & 6 & 7 & 8 & 9 & 10 & 11 & 12 & $\begin{array}{l}\text { Io- } \\
\text { tal }\end{array}$ & $\bar{x}$ \\
\hline $30-80$ & 1,2 & 2,0 & 1,2 & 2,0 & 1,5 & 0,5 & 1,2 & 1,9 & 1,2 & 1,2 & 0,8 & 0,3 & 15,0 & 1,250 \\
\hline $20-130$ & 0,7 & 1,0 & 0,2 & 2.8 & 0.3 & 0,2 & 0.2 & 1,3 & 1,2 & 2,1 & $1,6)$ & 0,3 & 12,4 & 1,033 \\
\hline $130-180$ & 1,9 & 2,3 & 0,5 & 1,9 & 0.2 & 2,6 & 0,2 & 0,3 & 0,2 & 3,3 & $2,0)$ & 1.3 & 16,7 & 1.391 \\
\hline $180-230$ & 0,7 & 1,5 & 0,4 & 1.7 & 1,7 & $2,4 \mid$ & 1,8 & 0,2 & 0,2 & 0.9 & 1,6 & 2,1 & 15.7 & 1,266 \\
\hline $230-280$ & 0,3 & 0,5 & 1,9 & 1,0 & 0,9 & 1,8 & 0.4 & 1,5 & 1.0 & 0,1 & 1,0 & 0,5 & 11,8 & 0,963 \\
\hline $280-330$ & 1,0 & 3,0 & 1,2 & 0,6 & 1,5 & 1,0 & 1,6 & 3,0 & 0,2 & 0,7 & 2,0 & $0,1 \mid$ & 16,5 & 1,375 \\
\hline $\begin{array}{l}\text { Dias apos } \\
\text { parto: } \\
10-30\end{array}$ & 0,5 & 0,5 & 0,1 & 0,2 & 1,2 & 2,8 & 1,5 & 1,6 & 0.7 & $1, \%$ & 1,6 & 0,7 & 11,8 & 0.983 \\
\hline
\end{tabular}

ANLISE DA VARINACIA

\begin{tabular}{l|r|r|r|r}
\hline $\begin{array}{l}\text { Ponte de } \\
\text { Variaçäo }\end{array}$ & g.1. & S.Q. & Q.M. & F \\
\hline $\begin{array}{l}\text { Tratgmentog } \\
\text { Residuo }\end{array}$ & $\begin{array}{r}6 \\
77\end{array}$ & $\begin{array}{l}2,33 \\
47,13\end{array}$ & $\begin{array}{l}0,3883 \\
0,61207\end{array}$ & 0,63 \\
\hline Total & 83 & 49,46 & & \\
\hline
\end{tabular}


Tabela V - Amilase: no sôro de éguas p.s. i. durante a gestação e após parto.

Os valores indicados representam unidades King por $100 \mathrm{~m} 1$ de sôro.

\begin{tabular}{|c|c|c|c|c|c|c|c|c|c|c|c|c|c|c|}
\hline $\begin{array}{l}\text { Dias apōs } \\
\text { cobertura }\end{array}$ & 1 & 2 & 3 & 4 & 5 & 6 & 7 & 8 & 9 & 10 & 11 & 12 & $\begin{array}{l}\text { To- } \\
\text { tal }\end{array}$ & $\bar{x}$ \\
\hline $30-80$ & 7,0 & 10,2 & 8,0 & 9,0 & 8,5 & 7,0 & 8,4 & 7,0 & 7,8 & 6,0 & 5,0 & 6,0 & 89,9 & 7,491 \\
\hline $80-130$ & 6,9 & 12,5 & 8,4 & 6,0 & 6,9 & 8,6 & 14,3 & 10,7 & 12,4 & 6,1 & 12,5 & 8,2 & 113,5 & 9,458 \\
\hline $130-180$ & 6,7 & 8,8 & 5,9 & 9,5 & 8,4 & 11,8 & 11,0 & 11,8 & 5,4 & 7,4 & 6,3 & 8,9 & 101,9 & 8,491 \\
\hline $180-230$ & 7,3 & 7,8 & 8,3 & 6,2 & 7,3 & 10,3 & 10,9 & 8,8 & 4,9 & 6,9 & 6,6 & 8,8 & 94,1 & 7.841 \\
\hline $230-280$ & 6,9 & 6,5 & 8,2 & 7,4 & 5,0 & 6,9 & 10,3 & 10,0 & 5,2 & 6,9 & 4,7 & 6,9 & 84,9 & 7.983 \\
\hline $280-330$ & 5,0 & 4,8 & 6,1 & 6,4 & 9,2 & 6,7 & 10,0 & 8,2 & 5,7 & 5,5 & 7,1 & 6,2 & 80,9 & 6,741 \\
\hline $\begin{array}{l}\text { Dias apos } \\
\text { parto: } \\
10-30\end{array}$ & 5,5 & 5,2 & 5,6 & 6,9 & 6,5 & 6,0 & 8,6 & 7,0 & 4,6 & 6,5 & 6,5 & 7,6 & 77,4 & 6,450 \\
\hline
\end{tabular}

\begin{tabular}{l|c|c|c|c}
\hline $\begin{array}{l}\text { Fonte de } \\
\text { variaçao }\end{array}$ & g.1. & S.Q. & Q.M. & F \\
\hline $\begin{array}{l}\text { Tratamentos } \\
\text { Residuo }\end{array}$ & $\begin{array}{r}77 \\
277,64\end{array}$ & 3,6057 & \\
\hline Total & 83 & 357,27 & & $3,68^{*}$ \\
\hline
\end{tabular}




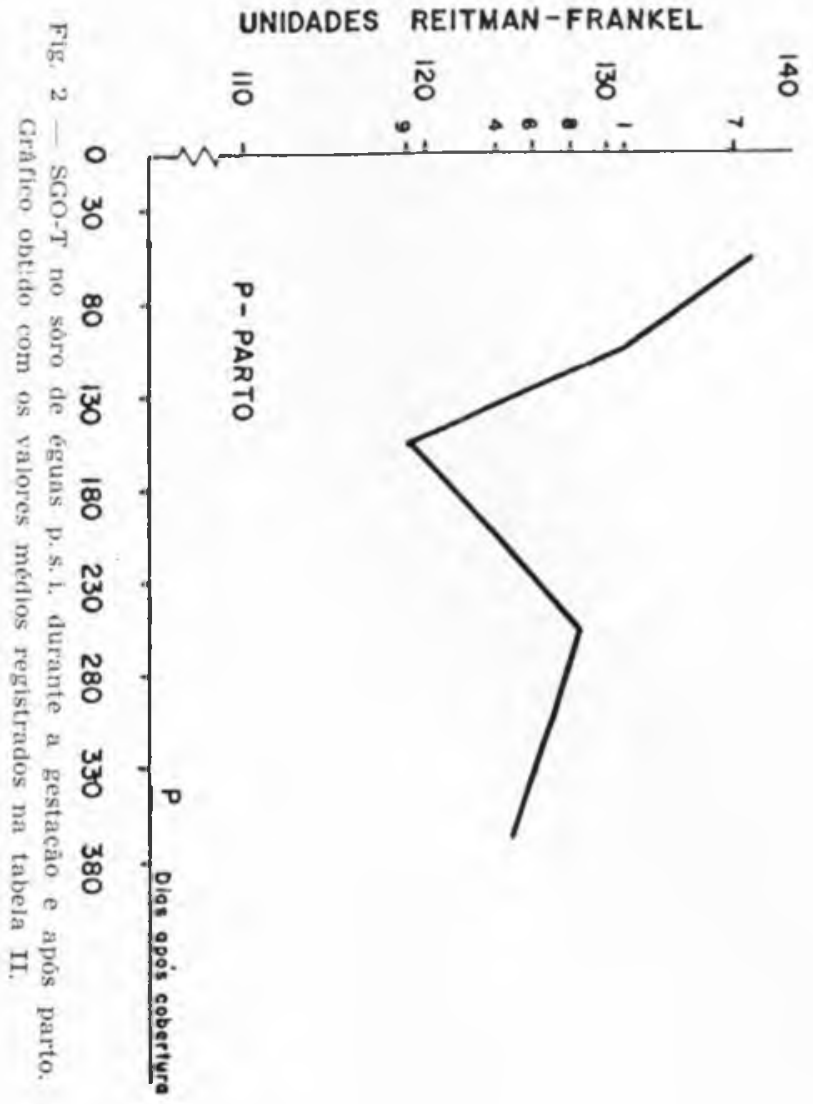

重|

엄

$\stackrel{5}{5}$

홓

\%

ํㅜㄹ

3

2

홍

동

ग

a

产

$=\frac{2}{3}$

-

है

\%

-

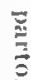


UNIDADES REITMAN FRANKEL

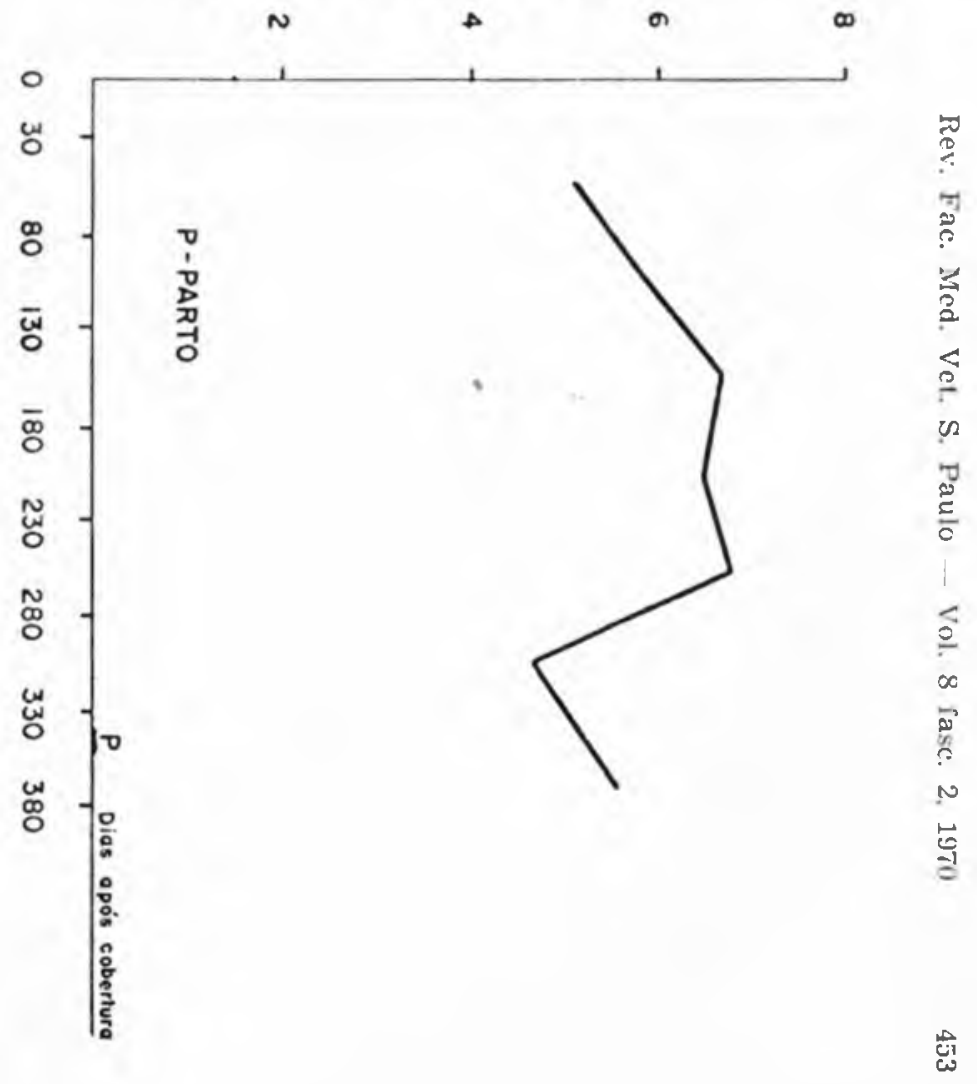




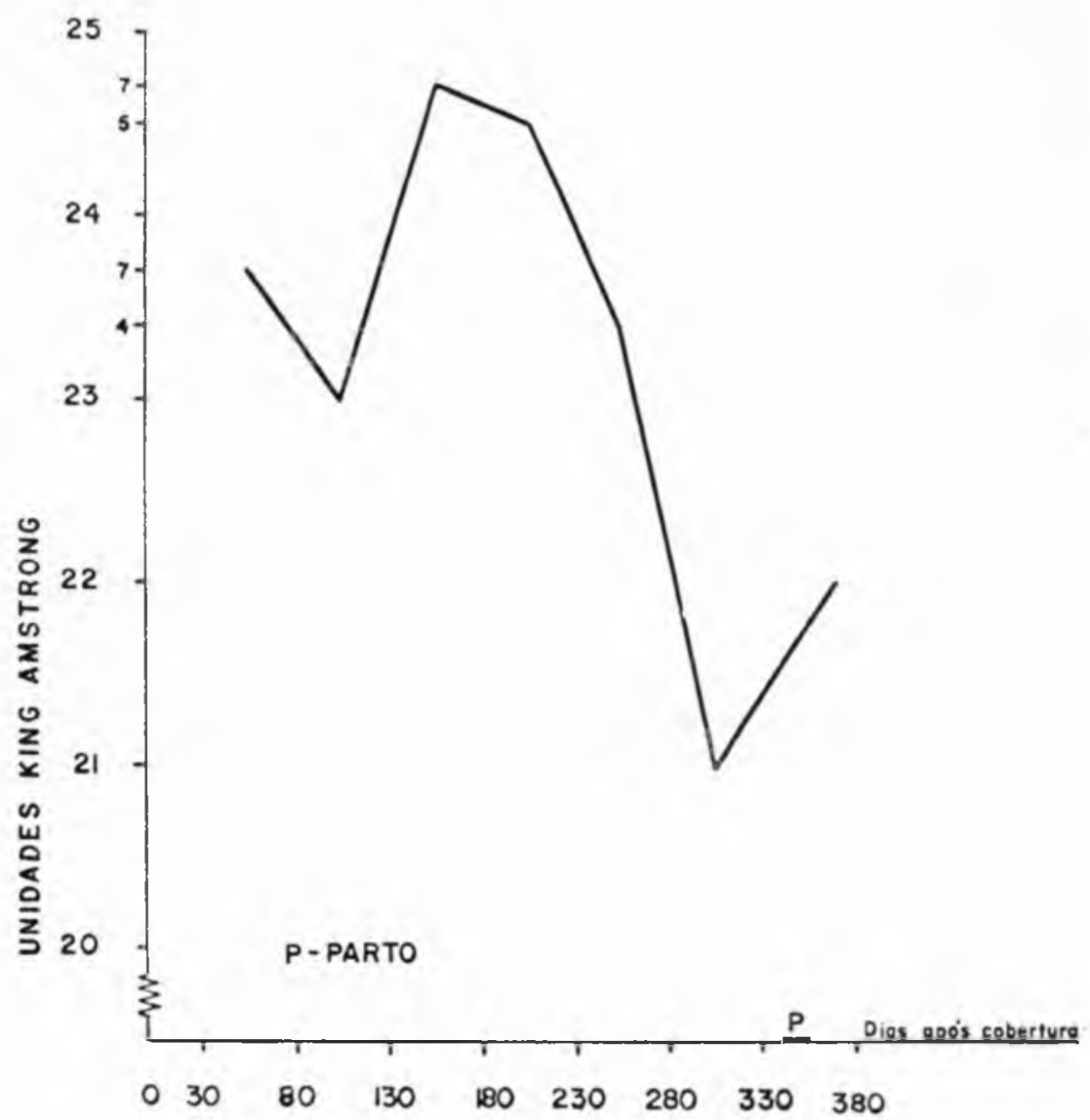

Fig. 3 - Fosfatase adcalina no sôro de çzuas p. s. 1. durante a gestacão e aposs patro. (irafieo olstido com os valores modios registratos nat tabela III 


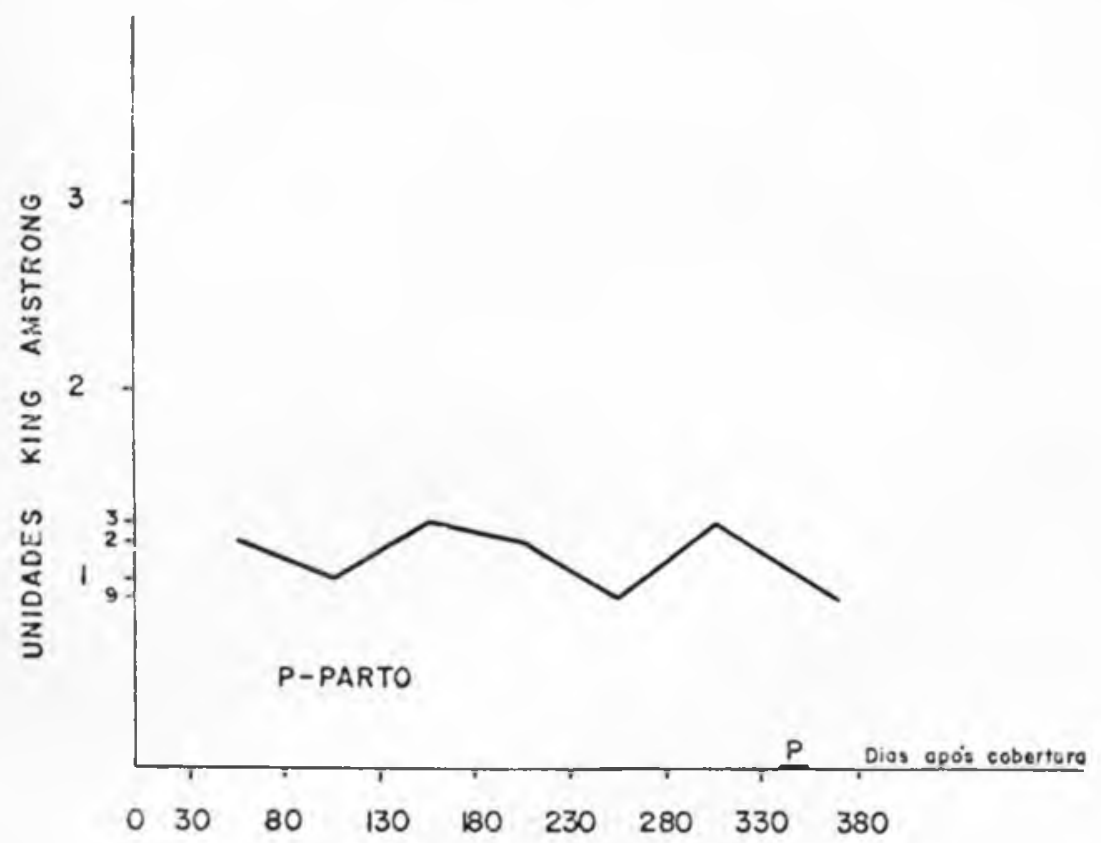

Fig. 4 - Fosfatase ácitla no sōro de éguas p.s. i. durante a gestacāo e após parto. Gráfico obtido com os valores médios registrados na tabela IV. 


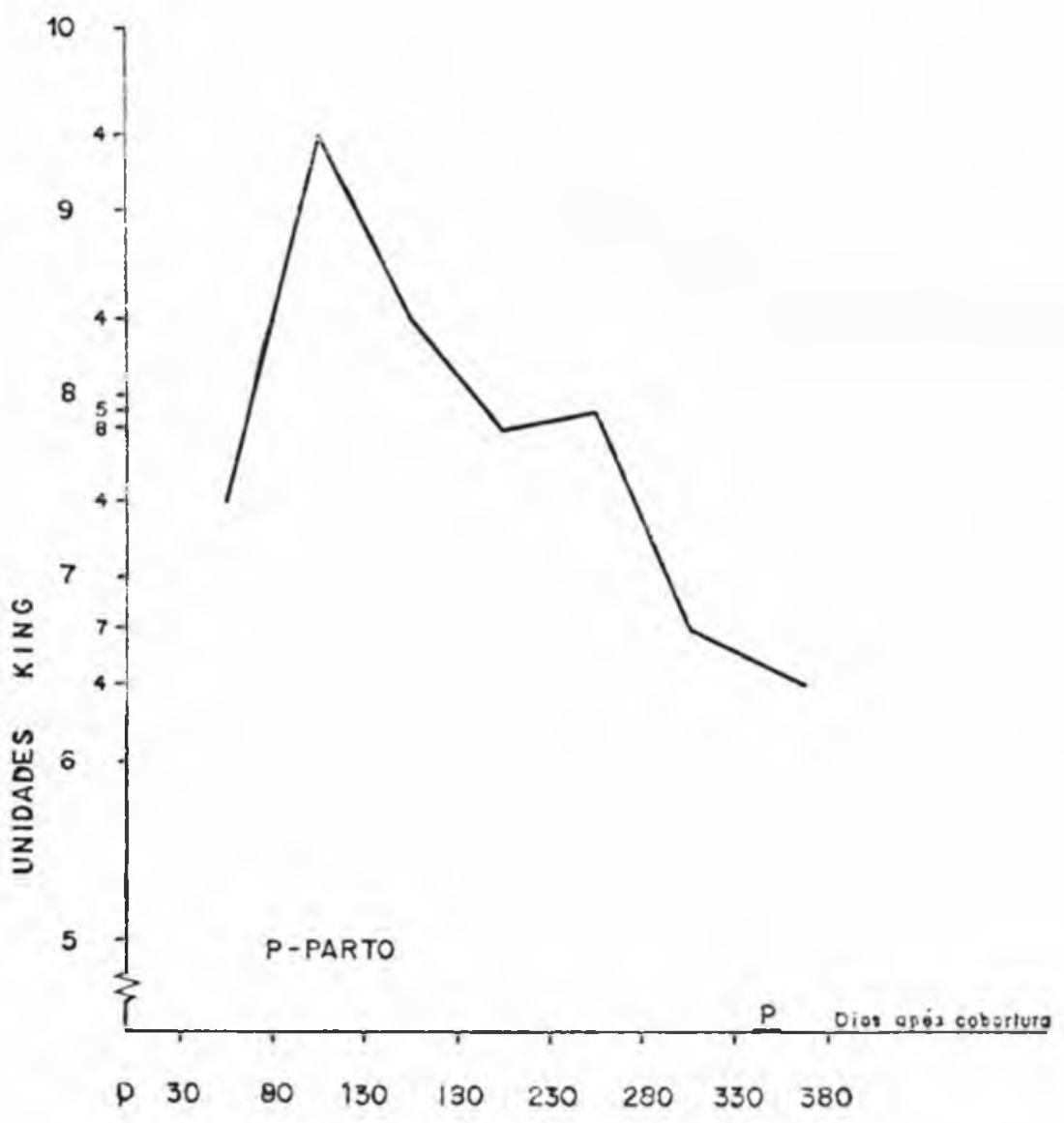

Fig. 5 - Amilase no sôro de éguas p.s. 1. durante a gestacão e após parto. Gráfico obtido com os valores médios registrados na tabeia $v$. 


\section{DISCUSSAOO}

As transaminases estudadas no presente trabalho, quer a SGP-T quer a SGO-T, revelaram o mesmo comportamento encontrado por outros autores.

Assim, Sato e Valenas (9) e Odebrecht (7), ao estabelecerem os niveis normais das transaminases acima aludidas em cavalos p.s.i de corrida e em treinamento, verificaram que o valor da SGO-T, expresso em unidades REITMAN-FrANKEL, era maior que o valor da SGP-T, fato a concordar com os nossos resultados.

Analisando os resultados referentes às transaminases, pudemos averiguar que, durante os diferentes periodos da gestação em que os niveis dessas enzimas foram determinados, não encontramos diferenças significantes entre êles. Nāo verificamos, portanto, em nenhum dos periodos estudados, seja aumento ou diminuição na atividade das transaminases. Na espécie humana, durante a gestação, Stone e cols. (10) nāo encontraram modificações no nivel da SGO-T, fato a concordar com nossos dados. Entretanto, Buonaccorsi (3), em bovinos, em desacórdo com nossas observações, verificou que a SGO-T, em relação às taxas dos animais contrỏles, manteve-se em niveis mais baixos nos primeiros três meses da gestação, os quais tenderam a elevar-se nos meses sucessivos, permanecendo, todavia, nos limites dos valores contrôles. A SGP-T acusou niveis sensivelmente altos, em relação aos valores dos contrôles, no primeiro quadrimestre da gestação. Característico foi o comportamento inverso das duas transaminases, havendo elevação de uma (SGO-T) com simultâneo abaixamento da outra (SGP-T).

O comportamento das fosfatases, ácidas e alcalina, mostrou-se diferente. Para a fosfatase ácida, não se observou variação no nível da sua atividade durante a gestação, mantendo-se dentro de valores tidos como normais por ODEBREcht (7) para o p.s.i de corrida, em regime de treinamento.

A fosfatase alcalina revelou, durante todo o periodo de gestação, niveis médios mais elevados do que os estabelecidos por ODEBRECHT (7) como niveis normais para o p. $\mathrm{s}$ i de corrida em regime de treinamento; os teores mais altos foram assinalados entre o $30^{\circ}$ e $280^{\prime \prime}$ dia da prenhez, e os mais baixos tanto entre $280^{\circ}$ e $330^{\circ}$ dia após a cobertura, como também de 10 a 30 dias após o parto.

Justificando êsse comportamento da fosfatase alcalina durante a gestação, lembramos BoDANSKY e cols. (2) que, em estudos feitos na mulher, observaram elevação na atividade da fosfatase sérica, sobretudo a partir do $7^{\circ}$ mês de gestação, admitindo que tal elevaçāo esteja relacionada com o aumento do metabolismo ósseo da gestante. 
Meranze e cols., citados por BOdANSKY e cols. (2), admitem que a elevação na atividade dessa enzima durante a gestação coincida com o período de maior ossificação fetal. Nāo podendo o feto, nessa ocasião, elaborar maior quantidade de fosfatase, a taxa adicional necessária seria produzida pelo organismo materno, sendo, assim, supridas as necessidades fetais.

Albright e Reifenstein, citados por KroOK e Lowe (6), dizem que altos niveis séricos da fosfatase indicam provàvelmente, aumento da atividade ostcoblástica desde que estejam ausentes outras causas como: doenças do figado e ictericia obstrutiva.

BODANSKY e JAFFE, citados por BODANSKY e cols. (2), lançaram o conceito da reatividade especifica controlada para reabsorção óssea, traduzida pela velocidade com que os minerais seriam retirados c, em seguida, novamente depositados nos ossos. A fosfatase sérica representaria, nestas condiçōes, um reflexo dessa reatividade especifica. Assim sendo, em tôdas as condições desencadeantes de maior formação óssea (juventude, osteoporose, etc.), haveria nivel mais alto de reatividade especifica, com maior atividade da fosfatase sérica. Por outro lado, em condições em que não há nítida formação óssea, como na senectude, o nivel da reatividade especifica é baixo, sendo paralelamente baixa a atividade da enzima aludida.

Segundo o conceito de BodANSKY e JAFFE, BODANSKY e cols. (2) admitem que na gestação haveria estimulos daquelas reações específicas do organismo envolvidas no problema das relaçoes metabólicas entre o feto e a mãe, motivado pela retirada, por parte do feto, do cálcio sanguíneo materno, para as necessidades de formaçāo óssea. Nestas condiçōes, ocorreria maior desmineralização dos ossos maternos, na tentativa de manter, dentro dos niveis normais, a calcemia. Consequentemente, aumentaria a atividade fosfatásica, com o intuito de restabelecer o equilibrio entre reabsorção e a deposição nos ossos da gestante.

Durante as fases da prenhez assinaladas no presente trabalho, isto é, de 30 a 80 dias, os niveis séricos da atividade da fosfatase alcalina mostraram-se já elevados, diferentemente da observação de BoDANSKY e cols. (2) na mulher, onde o nível da atividade foi mais alto no final da gestação. Possivelmente, essa maior atividade da enzima, por nós assinalada na égua p. s. i, estaria relacionada, segundo BoDANsky e cols. (2) com a maior labilidade do metabolismo ósseo materno e com a maior atividade osteoblástica, segundo Albright e Reifenstein, citados por Krook e Lowe (6).

Para a amilase, enzima tipicamente digestiva, os resultados mostraram niveis médios um pouco mais baixos do que os verificados por OderRecht (7) em p.s. i. e tidos como niveis normais. Por outro lado, houve incremento na atividade da amilase durante o periodo de 80 a 280 dias da prenhez. Torna-se para nós dificul- 
toso argumentar a respeito do incremento aludido. Segundo citação de Gerber (4), ainda que a amilase seja considerada como pâncreo-especifica, parece que 75 \%; de sua atividade sérica é proveniente do figado.

\section{SUMMARY}

The blood serum levels of SGP-T, SGO-T, alkaline and acid phosphatases and amylase have been carried out in pregnant thoroughbred mares.

Samples of blood have been collected in differents periods of the pregnancy as well as between 10-30 days post partum.

Only the data concerned to the alkaline phosphatase and amylase, from blood samples collected in some periods, have shown statistical significance.

\section{RFFLRE.VCIAS BIBLIOGRAFICAS}

1. BACILA, M.; BOABAID, K.; BRANCO, C. L.; CAMPELLO, A. P.; CAMPELLO, J. I.; CLAUSI, R.; INMYTRACZENKO, A.; DUARTE, J. H.; FOKAMA, G.; MFDINA, H. S. G.; ODEBRECHT, S.; SCHWAB, A.; VEIGA. A. A. \& VOSS, D. O. - Técnicas atualizadas de bioquímica clinica. Curitiba, Imprensa da Universidade do Paraná. 1962.

2. BODANSKY. M.; CAMPBELL. K. \& BALL, F. - Changes in serum calcium inorganic phosphate and phosphatase activity in pregnant women. Amer. J. clin. Path., Baltimore, 9:36-51, 1939.

3. BUONACCORSI. $\Lambda$. - Il fegato in gravidanza. Richerche emalo chimich nella bovina. An. Fac. Med. vet., Pisa, 1/:21-221, 1961.

4. GERBER. 11. - Aktintätsbestimmungen von Serumenzymen in der Velerinärmedizin. Schueiz Arch. Tierheilk, Zürich, 105:52 $5-550,1963$.

5. GOMES. F, P. - Curso de Fstatistica Experimental. Piracicaba. Escola Superior de Agricultura "Luiz de Queiroz". 1963.

6. KROOK, I. \& LOWE, J. F. - Nutritional secondary hyperparathyroidism in the horse. Puth. vet., Basel, 1 (suppl.), 1964.

7. ODEBRECH'T, S. - Niveis de enzimas séricas $\mathrm{em}$ cavalos p.s.i de cor. rida. Tese. Fscola de Agronomia c Veterinária da Universidade do $\mathrm{Pa}-$ raná. Curitiba, 1963.

8. REITMAN. S. \& FRANKEL, S. - In: IOVINE, F.; GAYA, F. R. \& VILLA. J. C. - Fotocolorimetria Clinica. Buenos Aires, Editorial Universitária. 1959.

9. SATO, S. A. \& VAllENAS, P. A. - Las transaminasas séricas SGO-T y SGP-T em caballos pura sangre de carrera. Rev. Fuc. Med. vet., Lima. $15: 231-243.1960$.

10. STONE, M. L.; I,FNDING, M. SLOBODY, L. B. \& MESTERN, J. Glutamic oxalacetic transaminase and lactic dehydrogenase in pregnancy. Amer. J. Obstet. Gynec. Mississipi, 80:104-107, 1960. 